\title{
Microwave Oven-drying Method for Determining Total Solids of Strawberries
}

\author{
Rosa Hemphill ${ }^{1}$ and Lloyd W. Martin ${ }^{2}$ \\ North Willamette Research and Extension Center, Oregon State \\ University, Aurora, OR 97002
}

Additional index words. Fragaria, freeze-drying, microwave-drying, percent dry weight

Total solids are an important part of the processing quality of strawberries used for drying, pureeing, and juicing. Between 1987 and 1990 at the North Willamette Research and Extension Center, Aurora, Ore., we evaluated strawberry (Fragaria $\times$ ananassa Duch.) selections for total solids by a long and expensive freeze-drying method. We have found that a low-power microwave-oven drying method reduces the drying time for total solids to $<1 \mathrm{~h}$, with results comparable to those obtained by either freeze-drying or nonvacuum oven-drying.

Becwar et al. (1977) reported that a microwave-drying method for pureed sweet corn (Zea mays L.) yielded percent moisture results within $1 \%$ of those determined by the Assn. of Official Analytical Chemists (AOAC) vacuum oven-drying method. Chin et al. (1985) reported no difference in total solids of tomato (Lycopersicon esculentum Mill.) products determined by microwave oven-drying and AOAC vacuum oven-drying, respectively. For determining total solids of high-sugar materials, the CEM Corp. (Mathews, N.C.) recommends drying pureed samples at low power to prevent scorching.

In our procedure, we homogenized a fivestrawberry sample (average weight 50 to 80 g) (Scott, 1984) for 2 min in a Waring blender (\#7011, Dynamics Corp. of America, New Hartford, Conn.). The berry puree was dried on 10- $\mathrm{cm}^{2}$ glass fiber sample pads (\#200150, CEM Corp.). The pads were predried by microwaving at $100 \%$ power $(630 \mathrm{~W}, 2450$ $\mathrm{MHz}$ ) for $10 \mathrm{~min}$ in a SAMP155 Solids and

Received for publication 1 May 1992. Accepted for publication 17 Aug. 1992. Oregon State Univ. Agr. Expt. Sta. Technical Paper no. 9882. Work was partially supported by a grant from the $\mathrm{Ag}$ ricultural Research Foundation. The cost of publishing this paper was defrayed in part by the payment of page charges. Under postal regulations, this paper therefore must be hereby marked advertisement solely to indicate this fact.

Research Assistant.

${ }^{2}$ Professor of Horticulture. Present address: Dept. of Horticulture and Forestry, Univ. of Arkansas, Fayetteville, AR 72701.
Moisture System (\#920080, CEM Corp.) and tared on a Mettler digital balance (AC 100S2, Mettler Instrument, Highttown, N.J.). About $5 \mathrm{~g}$ of puree is spread evenly over the tared pad and weighed immediately, since the puree starts evaporating on the pad. The square pads are folded to allow two opposite corners to turn up. Six pads are arranged on the rotating turntable $(6 \mathrm{rpm})$ of the CEM microwave dryer. The samples are dried for $30 \mathrm{~min}$ at $30 \%$ power $(189 \mathrm{MHz})$. The dried samples are weighed immediately, since the dried puree regains moisture quickly.

To compare the relative effectiveness of different drying methods, duplicate five-berry samples from five cultivars or selections were harvested from replicated plots on three or four dates in the 1991 season, weighed, frozen, and stored at $-18 \mathrm{C}$ for later use. Each sample was thawed $1 \mathrm{~h}$ and blended. The puree was divided into duplicate samples for microwave-drying, duplicate samples for freeze-drying, and single or duplicate samples for oven-drying. Total solids in the three methods were calculated as percent dry weight of the puree.

For microwave-drying, duplicate 5-g portions of the puree were microwave-dried by the method described above. Each pad with dried puree was redried in the microwave at $30 \%$ power for 2 or $30 \mathrm{~min}$ and reweighed immediately to see if dried weight differed with additional drying time.

For freeze-drying, duplicate 5- to $10-\mathrm{g}$ samples of the puree were weighed in pretared containers and dried for $48 \mathrm{~h}$ at $-50 \mathrm{C}$ and a midrun pressure of $20.7 \mathrm{~Pa}$ on a Labconco Freeze Dryer 3 (model 75200, Labconco Corp., Kansas City, Mo.). The vacuum

Table 1. Effect of drying method on total solids of strawberry puree (number of duplicate samples).

\begin{tabular}{llcc}
\hline & \multicolumn{3}{c}{ Drying method } \\
\cline { 2 - 4 } Criterion & $\begin{array}{c}\text { Microwave } \\
(30 \mathrm{~min})\end{array}$ & $\begin{array}{c}\text { Frecze } \\
(48 \mathrm{~h})\end{array}$ & $\begin{array}{c}\text { Oven } \\
(20-24 \mathrm{~h})\end{array}$ \\
\hline Total solids, mean & $10.4^{2}(42)$ & $10.1(42)$ & $10.1(35)$ \\
SE & 0.20 & 0.19 & 0.23 \\
\hline z10.3\% after an additional 2 or 30 min of drying time. &
\end{tabular}

$10.3 \%$ after an additional 2 or 30 min of drying time. Chem. 68(6):1081-1083.
Table 2. Correlations (r) among total solids of strawberry purees determined by microwave-, freeze-. and oven-drying methods.

\begin{tabular}{llc}
\hline & \multicolumn{2}{c}{ Drying method } \\
\cline { 2 - 3 } Drying method & $\begin{array}{c}\text { Freeze } \\
(48 \mathrm{~h})\end{array}$ & $\begin{array}{c}\text { Oven } \\
(20-24 \mathrm{~h})\end{array}$ \\
\hline Microwave, 30 min & $0.949^{\mathrm{z}, \cdots *}$ & $0.923^{\mathrm{y}, * \cdots}$ \\
Freeze, 48 h & $0.837^{\mathrm{y}, \cdots}$ \\
\hline "Forty-two pairs of data. & \\
"Thirty-five pairs of data. \\
${ }^{* * *}$ Significant at $P \leq 0.001$.
\end{tabular}

was broken, and each dried sample was immediately weighed.

For oven-drying, single or duplicate samples $(5$ to $15 \mathrm{~g}$ ) of the puree were weighed in pre-tared containers, dried overnight at $60 \mathrm{C}$ in a Blue $\mathrm{M}$ oven (OV-490A-2, Blue M Electric, Blue Island, Ill.), and reweighed.

Duplicate sample results, when available, were averaged before calculation of correlation coefficients and paired $t$ tests.

Values for total solids were similar among freeze-dried, microwave-dried, and oven-dried methods (Table 1) and were significantly correlated (Table 2). No significant difference was detected by paired t test between values obtained by either freeze-drying or microwave-drying $(P>0.05)$. Drying time in addition to the first 30 min was not necessary $(P>0.05)$. Microwave-drying at $>30 \%$ power caused some scorching of the puree.

In summary, low-power microwave-drying provided total-solids values for strawberry puree that were highly correlated with those determined by either freeze-drying or ovendrying.

\section{Literature Cited}

Becwar, M.R., N.S. Mansour, and G.W. Varseveld. 1977. Microwave drying: A rapid method for determining sweet corn moisture. HortScience 12(6):562-563.

Chin, H.B., J.R. Kimball, Jr., J. Hung, and B. Allen. 1985. Microwave oven drying determination of total solids in processed tomato products: Collaborative study. J. Assn. Offic. Anal.

Scott, G. 1984. Strawberry fruit quality as affected by soil $\mathrm{pH}$, phosphorus, spring applied nitrogen, and time of harvest. MS Thesis, Oregon State Univ., Corvallis.

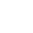

